\title{
Conscientizar para transformar: a educação pelo rádio no sertão do Seridó
}

\author{
Raising awareness to transform: education through radio in the Sertão Seridó \\ Sensibilización para transformar: educación a través de la radio en el Sertão do Seridó
}

Recebido: 25/09/2021 | Revisado:01/10/2021 | Aceito: 01/10/2021 | Publicado: 04/10/2021

\author{
Maria Dolores de Araújo Vicente \\ ORCID: https://orcid.org/0000-0001-6850-828X \\ Universidade Federal do Rio Grande do Norte, Brasil \\ E-mail: doloresvicente@yahoo.com.br \\ Juciene Batista Félix Andrade \\ ORCID: https://orcid.org/0000-0002-4590-2951 \\ Universidade Federal do Rio Grande do Norte, Brasil \\ E-mail: jucieneandrade@yahoo.com.br
}

\begin{abstract}
Resumo
O Movimento de Educação de Base - MEB, no sertão do Seridó, apresentou sua proposta de alfabetização através das Escolas radiofônicas. A Rádio Rural de Caicó foi o espaço educativo, utilizado para o desenvolvimento das ações do MEB no sertão seridoense. O objetivo desse trabalho é apresentar o conceito de conscientização que é referenciado na documentação de elaboração do MEB, a exemplo do relatório que encaminha publicações sobre o desenvolvimento do MEB entre os anos de 1961 a 1966. Servirá de análise teórica o trabalhado de Paulo Freire. A documentação do Movimento de Educação de Base encontra-se sob a custódia do LABORDOC (Laboratório de Documentação Histórica do CERES/UFRN) e sua trajetória entre os anos de 1960 a 1980, na cidade de Caicó. Apresentamos também como proposta teórica o trabalho de Fávero. A metodologia aplicada se dará através da análise das grades dos programas de rádio elaborados pelos professores/locutores e os relatórios do Movimento de Educação de Base, realizados no decorrer dos primeiros anos de atuação do MEB no Brasil. Analisar o conceito de conscientização através da grade dos programas transmitidos pela Rádio Rural nas décadas de 1960 a 1980 nos permite observar quais dinâmicas são apresentadas sob a influência do conceito de conscientização nas referidas programações. Programas que apresentam temas como: saúde popular, politização, evangelização, educação, nos coloca a pedagogização utilizada para erradicação do analfabetismo da população rural do Seridó, precisamente na cidade de Caicó.
\end{abstract}

Palavras-chave: MEB; Rádio; Educação; Conscientização.

\begin{abstract}
The Basic Education Movement -MEB, in the Sertão do Seridó, presented its literacy proposal through radio schools. The Rural Radio of Caicó was the educational space used for the development of MEB actions in the sertão sertão region. The objective of this work is to present the concept of awareness that is referenced in the documentation for the elaboration of the MEB, such as the report that forwards publications on the development of the MEB between the years 1961 to 1966. The work of Paulo Freire will serve as theoretical analysis. The documentation of the Basic Education Movement is under the custody of LABORDOC (Historical Documentation Laboratory of CERES/UFRN) and its trajectory from 1960 to 1980, in the city of Caicó. We also present as a theoretical proposal the work of Fávero. The methodology applied will be through the analysis of the schedules of radio programs prepared by the teachers/announcers and the reports of the Basic Education Movement, carried out during the first years of the MEB's operations in Brazil. Analyzing the concept of awareness through the grid of programs broadcast by Rádio Rural in the 1960s to 1980s allows us to observe which dynamics are presented under the influence of the concept of awareness in these programs. Programs that present themes such as: popular health, politicization, evangelization, education, introduces us to the pedagogy used to eradicate illiteracy in the rural population of Seridó, precisely in the city of Caicó.
\end{abstract}

Keywords: MEB; Radio; Education; Awareness.

\section{Resumen}

El Movimiento de Educación de Base - MEB, en el sertão del Seridó, presentó su propuesta de alfabetización a través de escuelas radiofónicas. Radio Rural de Caicó fue el espacio educativo utilizado para el desarrollo de las acciones del MEB en el sertão del Seridó. El objetivo de este trabajo es presentar el concepto de concienciación al que se hace referencia en la documentación del desarrollo del MEB, como el informe que recoge las publicaciones sobre el desarrollo del MEB entre los años 1961 y 1966. El análisis teórico se basará en la obra de Paulo Freire. La documentación del Movimiento de Educación Básica está bajo la custodia del LABORDOC (Laboratorio de Documentación Histórica del CERES/UFRN) y su trayectoria entre los años 1960 a 1980, en la ciudad de Caicó. También presentamos como propuesta teórica el trabajo de Fávero. La metodología aplicada ocurrirá a través del 
análisis de las parrillas de los programas de radio elaborados por los profesores/locutores y de los informes del Movimiento de Educación Básica, realizados en el curso de los primeros años de actuación del MEB en Brasil. El análisis del concepto de concienciación a través de los programas emitidos por Radio Rural en las décadas de 1960 a 1980 permite observar qué dinámicas se presentan bajo la influencia del concepto de concienciación en dichos programas. Programas que presentan temas como: salud popular, politización, evangelización, educación, nos sitúa la pedagogía utilizada para la erradicación del analfabetismo de la población rural del Seridó, precisamente en la ciudad de Caicó.

Palabras clave: MEB; Radio; Educación; Sensibilización.

\section{Introdução}

A educação através do rádio foi uma realidade apreciada nos sertões do Seridó no início da década de 1960. Pensar educação através do rádio já era realidade na capital do Estado do Rio Grande do Norte, Natal nos meados dos anos de 1940. O Movimento de Natal, ação executada pela Igreja Católica no espaço pós-guerra utilizou o rádio para propagar a alfabetização em massa da população rural, como também a politização e a evangelização dos espaços rurais.

As questões agrárias foram temas importantes na década de 1950 para a Igreja Católica1 ${ }^{1}$ Segundo Ferrari (1968 como citado em Paiva 2009, p. 27), no estado do Rio Grande do Norte existia uma enorme expressão de injustiças sociais em distribuição de terras: “os latifúndios com mais de 10 mil hectares ocupavam quase 20\% da área cultivada, enquanto ínfimas propriedades de menos de 10 hectares se comprimiam em $2 \%$ da área total”. A informação acima mostra bem o quadro social enfrentado pelos habitantes rurais reforçando os abismos e as desigualdades na sociedade brasileira. Diante desse quadro, surgiu a necessidade segundo Paiva, da constituição de uma "Missão Rural”, ação debatida na I Semana Rural, encontro ocorrido em janeiro de 1951, apoiado pela SIA (Serviço de Informação Agrícola vinculada ao Ministério da Agricultura) e pela Ação Católica Nacional, a época coordenado por Dom Hélder Câmara. Diante de um contexto de exploração no estado do Rio Grande do Norte, a missão rural surgiu com a proposta de educar o homem do campo e o bem estar das comunidades rurais ${ }^{2}$.

Emerge nesse ponto a centelha dos inúmeros projetos com o intuito de levar ao homem do campo noções de educação, politização, saúde, conscientização social.

Analisando essas questões, Dom Eugênio de Araújo Sales ${ }^{3}$ tomou como inspiração a experiência de erradicação do analfabetismo em Sutatenza (Colômbia), modelo de base paroquial, criado em 1947 pelo Padre José Salcedo, que utilizava o Rádio como ferramenta educativa ${ }^{4}$. Surgiu assim, as Escolas Radiofônicas de Natal $^{5}$ baseada em uma recepção organizada, com local reservado e monitor da comunidade (treinado para a função) e programação articulada localmente por “professores e funcionários do SAR” (Paiva, 2009), levando em consideração as necessidades locais.

O Movimento de Educação de Base agregou aos seus trabalhos a experiência das Escolas Radiofônicas do Movimento de Natal e apresentou ao Seridó essa experiência com a inauguração da Rádio Rural de Caicó no ano de 1963 e seis meses após sua inauguração programas voltados para "conscientizar" os seridoenses, como alfabetizar, politizar e os cuidados com a saúde, foram colocados no ar.

\footnotetext{
${ }^{1} \mathrm{O}$ final dos anos 50 caracteriza o início de mais um etapa na história da Igreja Católica do Brasil. Fatos importantes aconteceram no período. Aliás, a década de 50 é uma época que pode ser analisada como a era das mudanças, pois, a partir desse período, pode observar em setores religiosos e leigos modificações na maneira de exercer seu apostolado, "saindo das sacristias" e passando a interagir mais intensamente na sociedade (Paiva, 1992, p. 114).

${ }^{2} \mathrm{O}$ papel da Igreja, a partir desse momento, não se resumia apenas em missas, batizados, casamentos, enfim, em celebrações religiosas, mas passava a mobilizar e orientar o homem do campo para que se unissem e formassem seus próprios sindicatos e, através deles, lutassem por seus diretos (Silva, 2007, p. 26).

${ }^{3}$ Nos anos de 1950, Dom Eugênio Sales era o administrador apostólico da Diocese de Natal (Paiva, 2009).

${ }^{4}$ Em 1953, no Rio de Janeiro, por ocasião do Seminário Látino-Americano de Bem-Estar Rural, o Mons. Salcedo, discorrendo sobre o tema: "O rádio como meio de educação nas zonas rurais", relatou as experiências educacionais realizadas com os camponeses colombianos, desde 1947, através da Acción Cultural Popular (ACPO) (Paiva, 1999, p. 124).

${ }^{5}$ As Escolas Radiofônicas de Natal utilizaram material didático do SIRENA, a exemplo da radiocartilha, para $1^{\circ}$ série, adotada pela professora-locutora Carmem Fernandes Pedroza, primeira professora das Escolas Radiofônicas, em seu plano de "Plano Mensal de Atividades" para o $1^{\text {a }}$ e $2^{\mathrm{a}}$ séries, em Abril de 1963 (Paiva, 1999, p. 125).
} 
Mas, como esses programas em sua elaboração conseguiam alcançar seu objetivo de conscientizar e alfabetizar? Quais temas eram apresentados na dinâmica do rádio pelos professores/locutores no campo da saúde, política, evangelização e compreensão da realidade.

\section{Metodologia}

Para a realização do presente trabalho, se faz necessário apresentar os caminhos percorridos no tocante á metodologia aplicada no decorrer da pesquisa.

Fazer ciência é trabalhar simultaneamente com teoria, método e técnica, numa perspectiva em que esse tripé se condicione mutuamente: o modo de fazer depende do que o objeto demanda, e a resposta ao objeto depende das perguntas, dos instrumentos e das estratégias utilizadas na coleta de dados (Minayo, 2011,p. 622).

Durante a pesquisa é fundamental a análise bibliográfica para o fortalecimento e o amadurecimento do trabalho científico. "Apesar dessa multiplicidade e flexibilidade na caracterização das investigações científicas, geralmente todos os estudos realizam uma consulta à literatura, em busca de trabalhos simulares para delinear o cenário e/ou justificar o ineditismo e originalidade do tema" (Batista \& Kumanda, 2021, p. 3).

Paulo Freire (2001) é apresentado como uma das referências bibliográficas para o presente trabalho, assim como Fávero (2004), em sua discussão sobre o tema trabalhado. A pesquisa qualitativa é uma das escolhas para a fundamentação metodológica do trabalho. O verbo principal da análise qualitativa é compreender. Compreender é exercer a capacidade de colocar-se no lugar do outro tendo em vista que, como seres humanos, temos condições de exercitar esse entendimento (Minayo, 2011, p. 623). Analisar as programações escritas e preparadas pelos professores/ locutores do Movimento de Educação de Base, nos aproxima da realidade vivenciada pelos alunos das chamadas Escolas radiofônicas no Seridó durante as décadas de 1960 a 1980.

\section{A Educação de Base e o Processo de Conscientizar Através da Programação da Emissora de Educação Rural}

$\mathrm{Na} \mathrm{O}$ rádio na década de 60 foi apresentado aos sertões do Seridó como ferramenta educativa. A educação de base se fez necessário nos espaços identificados como "subdesenvolvidos". O decreto Lei $\mathrm{n}^{\circ}$ 50.370/maio de 1961, assinado no governo de Jânio da Silva Quadros e a CNBB (Conferência Nacional dos Bispos do Brasil), dando origem ao Movimento de Educação de Base, enfocava a necessidade de atuação em áreas do Brasil, reconhecidamente subdesenvolvidas, com altos índices de analfabetismo: as regiões Norte, Nordeste e Centro-Oeste. O trabalho de alfabetização em massa foi apresentado como uma possibilidade de aprender o mínimo: ler, escrever e contar e “(...) de habilidades profissionais, domésticas, artísticas, do cultivo de técnicas e emprego de novas tecnologias de produção, reprodução material, ao lado da compreensão mínima dos fenômenos naturais e das organizações sociais e sindicais (...)” (Medeiros, 2013, pp. 35-36).

Assim, alfabetizar era um dos compromissos do $\mathrm{MEB}^{6}$, se fazia necessário também construir na mentalidade das pessoas do campo um entendimento do sistema de dominação política e econômica aos quais estavam inseridos. Ou seja, educar para combater as injustiças sociais e compreender sua própria realidade. Dessa maneira, o conceito de conscientização pode ser entendido como: tomar posse da realidade; por esta razão, e por causa da radicação utópica que a informa; por um

\footnotetext{
${ }^{6}$ Os técnicos do MEB abordavam os camponeses como iguais, como pessoas cujas opiniões tinham grande importância, e que eram dignificadas por sua vida e seu trabalho (Kadt, 2007, p. 272).
} 
afastamento da realidade (Freire, 2001, p. 33). A conscientização atravessa toda uma construção alicerçada no discurso dos "donos da terra", apresentado uma realidade sem movimento, eminente das condições humanas dos que ali estavam.

A Emissora de Educação Rural de Caicó pertencente à Diocese foi parte importante na construção da "conscientização" de mulheres, homens e jovens seridoenses. O rádio foi colocado como ferramenta capaz de atravessar as fronteiras do distanciamento. Na época um elemento tecnológico capaz de vencer as distâncias e possibilitar o acesso à educação do homem do campo. Dessa maneira,

O rádio significava, de forma concreta, a tecnologia a serviço da educação do homem campesino. Rádio que, continuamente presente, levava a cada instante uma mensagem nova, abrindo enormes perspectivas. Era um rádio de ondas cativas, mas, ondas que levavam o camponês a se sentir importante, a tomar conhecimento do que acontecia no seu Estado, na sua região, no seu país e no mundo, pois, além das aulas, a Emissora de Educação Rural levava aos alunos das escolas radiofônicas diariamente, noticiários e variados programas educativos. (Paiva, 2009, p. 51).

A apropriação do rádio com propósitos educacionais revelou-se fenômeno transfronteiriço (Medeiros, 2008, p. 204).

As fronteiras encontradas pelos sertanejos relacionadas ao acesso aos espaços de educação formal, com o rádio, deixam de serem distantes para o contato com a conscientização e a alfabetização.

A Rádio Rural nasceu para transformar a educação e a cidadania. A parceria com o MEB constituiu-se um empreendimento em favor da educação do homem do campo, quando não existiam escolas e nem possibilidades de estrutura-las, de modo a atender a grande população campesina, na época (Araújo, 2013, p. 14).

O Movimento de Educação de Base - MEB utilizou o rádio como ferramenta educativa e proporcionou uma mudança de mentalidade no agir desses sertanejos ${ }^{7}$. A conexão entre a irradiação de conhecimento e as mudanças de atitudes deveria ser construída, no processo educacional, através de estratégias múltiplas da animação popular e da participação (Souza, 2006, p. 253). Na cidade de Caicó, estado do Rio Grande do Norte, educar para conscientizar, apareceu como propósito na elaboração dos programas radiofônicos elaborados pelos professores/locutores que utilizavam a animação popular como instrumento de aproximação com os alunos que em seus espaços ditos "distantes" e "subdesenvolvidos" conseguiam desenvolver o processo de conscientização e a da educação de base.

Existia uma pessoa no estúdio, o professor, que emitia os conteúdos pelo rádio. Em outros espaços físicos, que poderia ser sala, debaixo de uma árvore, uma pequena capela, ficava alguém que ajudava a interpretar aquilo que estava sendo dito pelo rádio. Esse era chamado de monitor. Após escutarem as aulas transmitidas pelo rádio, os alunos realizavam os exercícios sob sua orientação. Quando não conseguiam um espaço adequado para a escola, alguns monitores chegavam a reunir as turmas em suas próprias casas (Fonseca, 2012, p. 20).

Como a programação apresentada pelo MEB Caicó desenvolvia em sua grade o processo de conscientização com seus alunos/ouvintes? E como o rádio foi e continuou sendo ferramenta de grande alcance nos sertões seridoenses?

Lançados os questionamentos acima, se faz necessário analisar o que seria uma educação de base para o MEB. Educação de base é, principalmente, atender às necessidades do desenvolvimento da pessoa humana em todas as suas dimensões. (MEB, 1961, p. 9). A Educação de base simboliza a humanização do homem do campo.

Em seu trabalho sobre o conceito de conscientização, Paulo Freire faz referência ao que seria para ele o processo de conscientização. A conscientização é o olhar mais crítico possível da realidade, que a des-vela para conhecê-la e para conhecer

\footnotetext{
${ }^{7} \mathrm{O}$ rádio significava, de forma concreta, a tecnologia a serviço da educação do homem campesino. Rádio que, continuamente presente, levava a cada instante uma mensagem nova, abrindo enormes perspectivas. Era um rádio de ondas cativas, mas, ondas que levavam o camponês a se sentir importante, a tomar conhecimento do que acontecia no Estado, na região e no país e no mundo, pois, além das aulas, a Emissora Rural levava aos alunos das escolas Radiofônicas, diariamente, noticiários, e variados programas educativos (Paiva, 2009, p. 51).
} 
os mitos que enganam e que ajudam a manter a realidade da estrutura dominante (Freire, 2001, p. 33). O autor apresenta a importância do olhar crítico sobre a realidade vivenciada pelos que não eram considerados alfabetizados. Os considerados analfabetos estavam reféns as opressões dos que mantinham seus trabalhos.

Sob esta perspectiva, o analfabeto não é então uma pessoa que vive à margem da sociedade, um homem marginal, mas apenas um representante dos estratos dominados da sociedade, em oposição consciente ou inconsciente àqueles que, no interior da estrutura, tratam-no como uma coisa. Assim, quando se ensina os homens a ler e a escrever, não se trata de um assunto intranscendente de $b a, b e, b i, b o, b u$, da memorização de uma palavra alienada, mas de uma difícil aprendizagem para nomear o mundo (Freire, 2001, p. 87).

Para o autor, o processo de conscientizar se fazia necessário antes da aplicabilidade do processo de alfabetização. A conscientização de si como sujeito dinâmico e transformador da sua realidade, seria algo importante para alcançar resultados positivos na construção da alfabetização do jovem, da mulher e do homem sertanejo.

No início dos trabalhos do Movimento de Educação de Base, na década de 1960, a Igreja Católica, parte fundamental na idealização, construção e disseminação das atividades do MEB pelas regiões consideradas subdesenvolvidas, Norte, Nordeste e Centro-Oeste, no momento em que parte da Igreja caminhava por estradas consideradas progressistas ${ }^{8}$, a incorporação de líderes leigos locais, ajudavam na propagação das atividades do MEB como também no processo de conscientização.

Interessante analisar no relatório dos cinco primeiros anos de atividades do MEB no Brasil, o conceito de conscientização que reflete a retirada das lentes da alienação que impedia a noção de humanização.

A conscientização, na sua visão do mundo, é relativizável e, por si mesmo, não apresenta um critério de validade, que não seja o da própria situação histórica - o único modo possível de justificar a conscientização seria então partir daquilo que é anterior e que, por isso mesmo, funda a própria história, isto é, a pessoa na sua exigência de humanização. Ora, neste sentido, educação de base, isto é, educação que parte do que é fundamental, do que é primeiro, coincide com o próprio princípio da conscientização. Em última análise, uma conscientização válida é aquela que se preocupa com o homem no mundo, na sua dignidade de pessoa que transcende o mundo e cria um universo humano. Exatamente porque necessita de justificação de seu valor e, portanto, de racionalização, que compreenda e explique o seu processo a conscientização exige uma ideologia - justificação imanente do seu valor. Ora a validade desta ideologia não pode ser dada pela consciência histórica, que é variável também, mas por aquilo que é o fundamental da história: a própria pessoa humana nas suas exigências de humanizar-se. Aqui confluem educação de base e conscientização. (MEB, 1966, p. 13).

A apresentação sobre a temática da conscientização colocada pelo referido relatório nas regiões elencadas pelo movimento apresenta o conceito de conscientização definido pela Igreja Católica.

O contexto da realização do Movimento de Educação de Base apresenta um momento de "cuidado", voltado para os ideais libertários. Os leigos envolvidos nos trabalhos voluntários na Igreja Católica, compromissados em desenvolver atividades voltadas para perceber no outro um aliado no "combate" a mentalidade de oprimido.

O MEB, mesmo sendo um movimento de Igreja, não seguiu rigidamente suas diretrizes. Apesar de possuir uma estrutura verticalizada (equipes nacional, estadual e local), havia uma certa descentralização em suas atividades, permitindo a cada sistema nuclear desenvolver uma programação própria: Aliado a esse aspecto, o fato de ser um Movimento coordenados por leigos também contribuiu para essa diversificação, ao ponto de permitir a seus agentes, diferentes graus de envolvimento nas lutas dos trabalhadores por transformações sociais (Paiva, 1997, p. 117).

Os leigos são considerados importantes, não só pela dimensão das atividades, mas também na captação de recursos no tocante a manutenção dos trabalhos do Movimento de Educação de Base.

\footnotetext{
${ }^{8} \mathrm{O}$ catolicismo progressista no Brasil teve muitas fontes e, sem dúvidas, já vinha fermentando por algum tempo quando surgiu como coerente de idéias e atividades (Kadt, 2007, p. 84).
} 
Analisando as grades dos programas apresentados pelos professores/locutores é perceptível a aplicabilidade da dinâmica da conscientização colocada por Paulo Freire. A conscientização sanitária, politica e cultural, se faz presente nas narrativas da programação das aulas transmitidas pelas escolas radiofônicas, no caso em questão, pela Emissora de Educação Rural de Caicó. A oralidade, prática realizada no meio rural, foi fator importante para o desenvolvimento dos trabalhos do MEB nas comunidades. A familiaridade com a transmissão oral com certeza foi um fator facilitador da comunicação entre as comunidades rurais e as equipes de rádio (Souza, 2006, p. 273).

\section{A Programação Chega para Conscientizar e Transformar a Realidade do Seridoense}

O MEB transborda em sua programação, questões relacionadas à saúde, como também com a politização dos alunos/ouvintes ${ }^{9}$. No programa do dia 16 de maio de 1986, que tem como Assunto: Questão Social da saúde - Direitos dos trabalhadores.

Nos programas passados, já vimos vários aspectos da questão social da saúde, ou seja, dos problemas sociais que geram doenças como: a concentração de terra nas mãos dos ricos, o salário injusto paga os trabalhadores, o trabalho indigno e escravizante, e muitos outros. Vimos também que existem pessoas se beneficiando com a doença do povo. São os donos das grandes fábricas de remédios de farmácia. Bem, mas como falamos no início do programa, são vários os problemas sociais, que geram doenças no Brasil. Os trabalhadores são os quais mais são doentes, justamente por que vivem explorados no trabalho, forçando muito e ganhado quase nada. (Programação, 1986, p. 2).

No trecho em destaque, percebemos que questões voltadas para a saúde estavam alegoricamente relacionadas à política, ou melhor, uma conscientização de que a enfermidade do corpo era consequência dos interesses de uma classe considerada dominante, opressora e exploradora. Para que os direitos fossem respeitados, era necessário elencar os problemas que se enfrentava nas comunidades, e analisar as melhorias de vida resultantes do esforço e a união de todos (Programação, 1986, p. 2). Nesse momento acontecia a percepção da importância do coletivo ${ }^{10}$, da percepção do homem como transformador da sua realidade.

Conscientizar via rádio era tarefa colocada aos professores/locutores que despertavam em seus alunos/ouvintes a capacidade do entendimento da realidade de si e do mundo a sua volta. Durante as aulas, questões eram levantadas para o despertar da conscientização e politização ${ }^{11}$ desses alunos. Assunto como o ato de votar, a formação da consciência de eleitor, eram assuntos debatidos durante as aulas pelo rádio.

No programa do dia 27 de novembro de 1986, percebemos a preocupação com essa conscientização. Observando a programação da aula:

LOC. "O voto é secreto, livre, sagrado. É uma decisão séria feita pela consciência do eleitor. Tudo aquilo que diminui ou ilude, ou atrapalha a liberdade de votar e errado. Quem vende ou compra voto vai contra o bem da comunidade. É um Judas. O eleitor livre e consciente não vota por dinheiro, por calçado, por registro ou casamento de graça, por remédio, por medo. Dom Rino afirma que é homem ou mulher de respeito, quem não vai em conversa. Tem dignidade. Sabe que pelo voto pode lutar contra tudo o que está errado na sociedade, escolhendo o partido ou o candidato mais de acordo com suas idéias (Programação, 1986, p. 2).

\footnotetext{
${ }^{9}$ As aulas eram planejadas pelas professoras, procurando atender a realidade do homem do campo, dentro de procedimentos pedagógicos e exigências técnicas para o rádio (Paiva, 2002, p. 75).

$10 \mathrm{O}$ novo foi aplicar o mencionado método a uma educação diferente que não negava o saber do homem do campo, mas a partir dele procurar contribuir para a construção de novos conhecimentos que pudessem ajudá-los na melhoria de suas condições de vida, permitindolhe crescer, não apenas individualmente, mas junto com as demais pessoas de sua comunidade (Paiva, 2002, p. 76).

11 A politização abordava de um modo geral a situação de miséria que assolava o país, destacando dentre os muitos problemas: a fome, a mortalidade infantil, a falta de assistência médica, o analfabetismo, a concentração de terras nas mãos de poucos, a falta de crédito, baixos salários do trabalhador e a negligência dos políticos face a toda essa problemática (Paiva, 2002, p. 90).
} 
O processo de conscientização ${ }^{12}$ era trabalhado de diversas maneiras. Acima o locutor trabalha com a importância do voto "secreto, livre e sagrado". Alusão clara aos influenciadores dos votos de muitos trabalhadores rurais e certamente uma crítica ao conhecido voto de cabresto tão presente nas relações de com padrinhamentos. A estratégia de convencimento pelo discurso do locutor estava bem alicerçada em construir no ouvinte cativo a noção de responsabilidade coletiva, vender ou comprar votos relacionava-se a deslealdade, ao Judas traidor. Nada mais tocante na mentalidade cristã, do que o exemplo de Judas que traiu Jesus nas estratégias de convencimento. Outra estratégia eram as relações entre os conceitos de liberdade, respeito, dignidade e o voto como arma de domínio do trabalhador consciente em mudar sua própria condição de vida.

\section{Considerações Finais}

Conscientizar para o MEB significava a transformação de uma mentalidade oprimida para uma mentalidade da ação. A educação seria colocada como parte integrante desse conjunto voltado para mudança da realidade desse sertanejo. O rádio era apresentado como ferramenta importante para captação das massas. A Igreja utilizava dessa ferramenta como instrumento pedagógico não só para o que ela colocava como o combate ao analfabetismo nas regiões consideradas "subdesenvolvidas", mas valia-se da potência dessa ferramenta para a disseminação da sua doutrina e o combate as ideias comunistas da época, onde Deus não estaria presente nesse universo de transformação.

A Emissora de Educação Rural de Caicó colocou os sertões do Seridó no contexto das transformações das mentalidades dos que ali acreditavam na transformação através da educação. O rádio aparecia como aliado e peça de grande estima, já que não só era percebido como o aparelho de decoração das residências sertanejas, mas veículo transmissor da educação de base, da aproximação da realidade da pessoa humana.

Educar e civilizar através da consciência sanitária, dos programas elaborados para as Escolas Radiofônicas, configura o "desbravamento" dos caminhos do analfabetismo. Esse desbravamento apresenta não só as intenções educacionais, mas também as intenções políticas. O conscientizar através da educação é apresentar as normas de como deve agir, pensar e torna prática no cotidiano do sertanejo.

O presente trabalho nos coloca a importância sobre a pedagogização realizada através das ondas do rádio. O homem, a mulher e o jovem rural, em um momento de "apagamento" das luzes da consciência de si e da realidade de opressão a sua volta, percebem o rádio como instrumento capaz de alfabetizar, conscientizar e educar. Pesquisar o rádio como ferramenta pedagógica se faz necessário em um momento de grandes tensões, causadas principalmente pela pandemia do COVID-19, no campo da educação, onde, como pensar os trabalhos pedagógicos fora dos espaços formais de educação. O Movimento de Educação de Base nos apresenta que durante as décadas de 1960, foi possível conscientizar através do rádio, transformar mentalidades e proporcionar mudanças nos espaços rurais do Seridó.

\section{Referências}

Araújo, A. T. (Org.). (2013). Rural de Caicó, 50 anos no ar. Oito de Março Gráfica e Editora.

Azevedo, L. C. (2002). No tempo do rádio: Radiodifusão e Cotidiano no Brasil. 1923 - 1960. (Tese de Doutorado). Universidade Federal Fluminense. http://www3.carosouvintes.org.br/wp-content/uploads/Tese_Lia_Calabre.pdf

Batista, L. S.\& Kumanda, K. M. O. (2021). Análise metodológica sobre as diferentes configurações da pesquisa bibliográfica. Revista brasileira de iniciação científica (RBIC), 8, e021029, 1-17. Recuperado de https://periodicoscientificos.itp.ifsp.edu.br/index.php/rbic/article/view/113/235

Blois, M. (2003, setembro). Rádio Educativo no Brasil: Uma história em construção. Congresso Anual em Ciência da Comunicação, http://intercom.org.br/papers/nacionais/2003/www/pdf/2003_NP06_blois.pdf

\footnotetext{
${ }^{12}$ Para os agentes do MEB, a conscientização exigia a explicitação de uma ideologia que fornesse direção a seu trabalho político. Era uma tarefa de conjunto, a ser realizada com a colaboração de todos aqueles que queiram a promoção das populações exploradas e com a participação consciente e efetiva dessas populações (Fávero, 2006, p. 103).
} 
Fávero, O. (Org.). (1983). Cultura popular, educação popular: memória dos 60 anos. Graal.

Fávero, O. (2004, abril). MEB - Movimento de Educação de Base primeiros tempos: 1961 a 1966. Encontro Luso-Brasileiro de História da Educação, http://cremeja.org/a7/wp-content/uploads/2019/09/Historico_1961_1966_Osmar_Favero.pdf

Fávero, O. (2006). Uma pedagogia da educação popular: análise da prática educativa do MEB: Movimento de Educação de Base (1961/1966). Autores Associados.

Freire, P. (2001). Conscientização: teoria e prática da libertação: uma introdução ao pensamento de Paulo Freire. Centauro.

Fonseca, A. B. G. A representação da cultura popular nordestina: o Movimento de Educação de Base (MEB), no Rio Grande do Norte, 1961 a1965 (Dissertação de mestrado). Universidade Federal da Bahia, Faculdade de Comunicação, Salvador, BA, Brasil.

Kadt, E. (2007). Católicos Radicais no Brasil. UNESCO, MEC, 332. p - (Coleção Educação para todos).

Medeiros, M. L. (2008). Ideais Formativos de homem da Emissora de Educação Rural de Caicó. (Tese de Doutorado). Universidade Federal do Rio Grande do Norte. https://repositorio.ufrn.br/jspui/bitstream/123456789/14150/1/MarioLM.pdf

Minayo, M. C. S. (2012). Análise qualitativa: teoria, passos e fidediguidade. Ciência \& Saúde Coletiva 2012, 17(3), 621-626. https://www.scielo.br/j/csc/a/39YW8sMQhNzG5NmpGBtNMFf/?format=pdf\&lang=pt

Pereira, A. A., Shitsuka, D. M., Parreira, F. J. \& Shitsuka, R. (2018). Metodologia da pesquisa científica UFSM. https://repositorio.ufsm.br/bitstream/handle/1/ 15824/Lic_Computacao_Metodologia-Pesquisa-Cientifica.pdf?sequence=1

Paiva, M. (1997). Sociedade, educação e religião: o caso da ação educativa da Arquidiocese de Natal (1944-1964). Revista Educação Em Questão, 7(1/2), 107-123. Recuperado de https://periodicos.ufrn.br/educacaoemquestao/article/view/10239

Paiva, M. M. (Org). (2009). Escolas radiofônicas de Natal: uma histórica construída por muitos (1958-1966). Liber Livro Editora.

Pimentel, F. P. (2009). O Rádio Educativo Brasileiro, uma visão histórica. (2a ed.). Soarmec.

Roldão, I. C. C. (2006, setembro). O Rádio Educativo no Brasil: Uma reflexão sobre suas possibilidades e desafios. Congresso Brasileiro de Ciências da Comunicação. http://www.intercom.org.br/papers/nacionais/2006/resumos/R0905-1.pdf

Silva, M. A. O. (2007). Evangelizar e politizar: O sentido da atuação da Igreja Católica com os Sindicatos de Trabalhadores Rurais do Seridó Potiguar (19641979). (Dissertação de Mestrado). Universidade Federal do Rio Grande do Norte.https://repositorio.ufrn.br/jspui/bitstream/123456789/1377 4/1/EvangelizarPolitizarSentido_Silva_2007.pdf

Souza, C. M. (2007). Pelas ondas do rádio: cultura popular, camponeses e o MEB. Tese de Doutorado, Faculdade de Filosofia, Letras e Ciências Humanas, Universidade de São Paulo. www.teses.usp.br. doi:10.11606/T.8.2007.tde-11072007-100422.

Wanderley, L. E. W. (2014). MEB e educação popular. Revista Em Pauta, 12(33), 97-107. https://www.e-publicacoes.uerj.br/index.php/revistaempauta/artic le/view/13027/10145. https://doi.org/10.12957/rep.2014.13027 